\title{
Pulmonary tuberculosis due to Mycobacterium bovis
}

\author{
E G L WILKINS, R J GRIFFITHS, C ROBERTS \\ From the Public Health Laboratory, Fazakerley Hospital, Liverpool
}

\begin{abstract}
During 1969-84 Mycobacterium bovis was isolated from 20 patients with pulmonary tuberculosis. This represented less than $1 \%$ of the total cases of respiratory tuberculosis confirmed bacteriologically at the Liverpool Public Health Laboratory during this period. All 20 patients were considered to have reactivated disease and all presented with the typical features of respiratory tuberculosis. During the same period four cases of pulmonary infection by Mycobacterium africanum were recognised. This organism is difficult to differentiate from $M$ bovis and failure to distinguish the two mycobacteria could lead to a misleading epidemiological picture of bovine tuberculosis in man.
\end{abstract}

A retrospective review of respiratory isolates identified at the Liverpool Public Health Laboratory from 1969 to 1984 was undertaken to ascertain the extent of Mycobacterium bovis infection in pulmonary tuberculosis in the Merseyside region.

\section{Methods}

Nineteen of the mycobacteria identified were primary isolations made at this laboratory and five were referred from neighbouring hospitals for identification of species and testing for drug susceptibility. For decontamination of sputum samples we used Nassau's and Petroff's methods in conjunction, and specimens were then inoculated on to neutral and acidified Lowenstein-Jensen and pyruvic acid media. ${ }^{1}$ These were incubated at $37^{\circ} \mathrm{C}$ and examined at weekly intervals for up to two months before being discarded. Mbovis was differentiated from $M$ tuberculosis initially by its dysgonic growth with enhancement by pyruvate and by its resistance to pyrazinamide. Since 1977 failure to reduce nitrate or synthesise niacin and susceptibility to thiopen-2carboxylic acid hydrazide have been used as confirmatory tests; oxygen preference was not determined. M bovis is distinguishable from $M$ africanum by its resistance to pyrazinamide and this was determined at the Tuberculosis Reference Laboratory, Cardiff.

Drug sensitivity testing was performed by the resistance ratio method. ${ }^{2}$ Isolates showing a ratio of four or more when compared with standard sensitive

Address for reprint requests: Dr C Roberts, Public Health Laboratory, Fazakerley Hospital, Liverpool L97AL.

Accepted 21 January 1986 strains were regarded as being resistant. Epidemiological and clinical information was obtained from the laboratory records and, when available, patient's case notes.

\section{Results}

Twenty four patients with pulmonary tuberculosis were found to be infected with Mbovis or $M$ africanum, representing $1 \cdot 1 \%$ of all patients with mycobacteria identified from the respiratory tract during the 15 years. Organisms were identified as M bovis (16) or Mafricanum (4) according to their susceptibility to pyrazinamide (table 1 ). The four remaining isolates were not tested for pyrazinamide sensitivity, but the ages of the patients (49-80 years) and the fact that they had done no foreign travel makes it likely that they were $M$ bovis. In support of this, all four patients had either a past history of tuberculosis diagnosed in the British Isles at least 25 years previously or concurrent isolation of the same organism from a non-respiratory site (which is more common with $M$ bovis than $M$ africanum infection ${ }^{3}$ ), or both features. All 20 patients with pulmonary disease due to $M$ bovis ( 16 confirmed and four presumed) were caucasian with an age range of 34-80 years and a near even distribution between the sexes $(11$ men and nine women). Four patients had identical organisms isolated from non-respiratory sites (bone (2), spinal fluid (1), and lymph node (1)). All four cases of $M$ africanum infection were identified in immigrant families, the ages of the patients being 3 months and 25,40 , and 56 years; no isolates were recovered from outside the respiratory tract. The sensitivity pattern of $M$ bovis isolates to antituberculous drugs is shown in table 2 . 
Table 1 Numbers (and percentages) of mycobacterial species isolated at Liverpool Public Health Laboratory, 1969-84 (means with standard deviations in parentheses)

\begin{tabular}{lllll}
\hline Site & M tuberculosis & M bovis & Mafricanum & Atypical mycobacteria \\
\hline Pulmonary & $2116(94 \cdot 0)$ & $20(0 \cdot 9)$ & $4(0 \cdot 2)$ & $111(4 \cdot 9)$ \\
Extrapulmonary & $428(85 \cdot 6)$ & $57(11 \cdot 4)$ & $-4(0 \cdot 1)$ & $15(3 \cdot 0)$ \\
Total & $2544(92 \cdot 5)$ & $77(2 \cdot 8)$ & $126(4 \cdot 6)$ \\
\hline
\end{tabular}

Table 2 Sensitivities of $M$ bovis to antituberculous drugs

\begin{tabular}{llc}
\hline Drug & Total tested & \% resistant \\
\hline Streptomycin & 20 & 5 \\
Isoniazid & 20 & 10 \\
Rifampicin & 19 & - \\
Ethambutol & 19 & 9 \\
Ethionamide & 11 & 64 \\
p-aminosalicylic acid & 14 & 100 \\
Pyrazinamide & 16 & \\
\hline
\end{tabular}

Details of 13 of the 20 patients with $M$ bovis infection were available. Three gave a history of past tuberculous disease (two remote, one recent) and a further three had radiological evidence suggesting previous infection (lung shadowing in two and abdominal calcification in one). Eight patients had conditions that may have predisposed them to the development of disease: three had achlorhydria, two inflammatory bowel disease, and one rheumatoid arthritis. A further patient was receiving corticosteroid treatment and another presented shortly after a routine operation. Seven deaths occurred, active pulmonary tuberculosis being the underlying cause in two and a contributory cause in three; the remaining two patients died from unrelated causes. Clinical and radiological features did not differ from those found with $M$ tuberculosis infection.

\section{Discussion}

The first bacteriologically confirmed case of bovine pulmonary tuberculosis in man was reported in
$1909^{4}$ and further investigations over the next three decades showed that $1-3 \%$ of all cases of respiratory tuberculosis resulted from $M$ bovis infections. ${ }^{56}$ Since the widespread adoption of milk pasteurisation by the dairy industry and the completion of the attested herds scheme in 1960, the chances of contracting infection directly or indirectly from cattle have become negligible. Hence present day isolates of $M$ bovis nearly always represent a recrudescence of old primary infection. Lesslie et al in $1972^{7}$ found that in many rural districts over half the tuberculin reactors born before 1950 had been sensitised with $M$ bovis, which implies that a sizeable reservoir of dormant bovine tubercle bacilli still exists in adults that can, potentially, be reactivated. Primary infections may occasionally be contracted abroad or may result from contact with cases of open pulmonary tuberculosis due to reactivated $M$ bovis, ${ }^{3}$ and this is thought to explain why new cases of $M$ bovis infection are still occurring in children, albeit very rarely. ${ }^{38}$ Although there was evidence of past tuberculosis in only half the cases of $M$ bovis in our series, all 20 were caucasians born before 1950 and none had a history of recent foreign travel. Hence the likelihood is that all were suffering from reactivated disease.

In a recent study of bacteriologically confirmed cases of pulmonary tuberculosis in England and Wales, ${ }^{9}$ the proportion of $M$ bovis isolates was $0.8 \%$, which is very similar to the proportion in this study $(0.9 \%)$. The percentage of total $M$ bovis isolates recovered from the respiratory tract has ranged from $39 \%$ in Scotland to $89 \%$ in Czechoslovakia in 13 articles published in the last two decades (table 3). ${ }^{39-20}$

Table 3 Pulmonary tuberculosis caused by bovine strains

\begin{tabular}{llclc}
\hline Region or country & Years of study & No of isolates & \% pulmonary & Ref \\
\hline South East England & $1977-9$ & 63 & 44 & 3 \\
England and Wales & $1978-9$ & 20 & 55 & 9 \\
West Scotland & $1963-5$ & 33 & 39 & 10 \\
Ontario & $1964-70$ & 31 & 42 & 11 \\
Netherlands & $1972-5$ & 125 & 89 & 12 \\
Czechoslovakia & $1960-75$ & 55 & 50 & 13 \\
Sweden & $1974-5$ & 12 & 86 & 15 \\
Czechoslovakia & $1974-8$ & 122 & 50 & $16-20$ \\
United States* & $1954-80$ & 12 & 30 & - \\
Merseyside Region & $1969-84$ & 81 & & \\
\hline
\end{tabular}

*Compiled from five reports. 
Most patients in Czechoslovakia had had contact with tuberculous cattle, explaining the much higher incidence of respiratory bovine tuberculosis in that country and confirming the importance of aerosol transmission of $M$ bovis from infected cows. ${ }^{1416}$ In the present study respiratory isolates of $M$ bovis represented $30 \%$ of the total number of bovine strains recovered from all sites. In all but one ${ }^{3}$ of the studies mentioned the compounding effect of the closely related African "bovine" variant (syn Mafricanum), cannot be assessed. ${ }^{8}$ This can be distinguished from $M$ bovis only by assessment of its sensitivity to pyrazinamide, and this is often restricted to specialised centres. The failure to differentiate $M$ bovis from $M$ africanum may give rise to a false epidemiological picture of bovine tuberculosis in man.

There is no evidence to suggest that pulmonary infection by $\boldsymbol{M}$ bovis differs clinically, radiologically, or in its postmortem appearances from that due to $M$ tuberculosis. All patients on whom information was available suffered typical "tuberculosis" that was indistinguishable from the disease caused by human strains. Why $M$ bovis fails to maintain itself in the human population through "open" cases in a manner analogous to $M$ tuberculosis is not known.

We are grateful to Miss Karen Whalley for secretarial help.

\section{References}

1 Grange JM. The mycobacteria. In: Parker MT, ed. Topley and Wilson's Principles of bacteriology, virology and immunity. Vol 2. 7th ed. London: Edward Arnold, 1983.

2 Grange JM. Mycobacterial diseases. Bath: Edward Arnold, 1980:46-55. (Current Topics in Infection Series No 1.)

3 Collins $\mathrm{CH}$, Yates MD, Grange JM. A study of bovine strains of Mycobacterium tuberculosis isolated from humans in South East England, 1977-79. Tubercle 1981;62:113-6.

4 Griffiths A. Further investigations of the type of tubercle bacilli occurring in the sputum of the phthisical person. Br Med J 1914;i:1171-5.

5 Griffiths AS. Bacillus tuberculosis. In: A system of bacteriology in relation to medicine. Vol V. London: HMSO, 1930:191-9.

6 Cutbill LT, Lynn A. Pulmonary tuberculosis of bovine origin. Br Med J 1944;i:283-5.

7 Lesslie IW, Magnus K, Stewart CJ. The prevalence of bovine type tuberculosis infection in man in the English rural population. Tubercle 1972;53:198-204.

8 Collins $\mathrm{CH}$, Grange JM. The bovine tubercle bacillus. $J$ Appl Bacteriol 1983;55:13-29.

9 Davies PDO, Humphries MJ, Byfield SP, et al. Bone and joint tuberculosis. A survey of notification in England and Wales. J Bone Joint Surg (Br) 1984;66:326-30.

10 Barrie JD, Burch LG. Human infections with bovine tuberculosis in the West of Scotland 1963-65. Scot Med J 1966;11:436-9.

11 Wigle WD, Ashley MJ, Kilhough EM, Cosens M. Bovine tuberculosis in humans in Ontario. Am Rev Respir Dis 1972;106:528-33.

12 Schonfeld JK. Infectie door boviene tuberkelbacterien bij de mens in Nederland in de periode 1972-1975. Ned Tijdschr Geneesk 1978;122:217-9.

13 Truksova B, Kithierova E, Mikova Z, Svandova E. Tuberkulosa vylovana bovinnimi mykobakterieme. Cas Lek Cesk 1978;117:229-302.

14 Sjogren I, Hillevdal O. Bovine tuberculosis in manreinfection or reactivation. Scand $J$ Respir Dis 1978;59:167-70.

15 Kubin M, Svandova E. Bakteriologicky prukaz Mycobacterium bovis $\mathrm{u}$ lidi $\mathrm{v}$ obdobi po elimanaci tuberkulozy skotu. Studia Pneumologica et Phthiseologica Cachoslovaca 1982;42:182-7.

16 Anonymous. Bovine tuberculosis-Maryland [Editorial]. Morbidity and Mortality Weekly Returns 1978;27:108, 113.

17 Karlson AG, Carr DT. Tuberculosis caused by Mycobacterium bovis. Report of 6 cases: 1954-1968. Ann Intern Med 1970;73:979-83.

18 Damsker B, Bottone EJ, Schieierson SS. Human infections with Mycobacterium bovis. Am Rev Respir Dis 1974;110:446-9.

19 Dreesen DW, Wood AR. A human case of Mycobacterium bovis infection in Georgia. Am Rev Respir Dis 1970;101:289-92.

20 Jones PG, Silva J. Mycobacterium bovis meningitis. JAMA 1982;247:2270-1. 